\title{
Do Patients Maintain Proper Long-Term Cardiopulmonary Fitness Levels After Cardiac Rehabilitation? A Retrospective Study Using Medical Records
}

\author{
Chul Kim, MD, $\mathrm{PhD}^{1}$, Hee Eun Choi, $\mathrm{MD}^{2}$, Jin Hyuk Jang, $\mathrm{MD}^{1}$, \\ Jun Hyeong Song, $\mathrm{MD}^{1}$, Byung-Ok Kim, MD, $\mathrm{PhD}^{3}$
}

\begin{abstract}
${ }^{1}$ Department of Rehabilitation Medicine, Sanggye Paik Hospital, Inje University College of Medicine, Seoul;
${ }^{2}$ Department of Rehabilitation Medicine, Haeundae Paik Hospital, Inje University College of Medicine, Busan;

${ }^{3}$ Department of Internal Medicine, Sanggye Paik Hospital, Inje University College of Medicine, Seoul, Korea
\end{abstract}

Objective To examine whether patients who participated in a cardiac rehabilitation (CR) program after hospitalization for acute coronary syndrome maintained cardiorespiratory fitness (CRF) in the community. Methods We conducted a retrospective study including 78 patients who underwent percutaneous coronary intervention or coronary artery bypass graft surgery at our hospital's cardiovascular center and participated in a CR program and a 5-year follow-up evaluation. Patients were divided into a center-based CR (CBCR) group, participating in an electrocardiography-monitored exercise training in a hospital setting, and a home-based CR (HBCR) group, receiving aerobic exercise training and performed self-exercise at home.

Results No significant differences were found between groups ( $p>0.05$ ), except the proportion of non-smokers (CBCR 59.5\% vs. HBCR 31.7\%; $\mathrm{p}=0.01$ ). In both groups, the maximal oxygen consumption $\left(\mathrm{VO}_{2 \max }\right)$ increased significantly during the first 12 weeks of follow-up and remained at a steady state for the first year, but it decreased after the 1-year follow-up. Particularly, $\mathrm{VO}_{2 \max }$ at 5 years decreased below the baseline value in the HBCR group. In the low CRF group, the CRF level significantly improved at 12 weeks, peaked at 1 year, and was still significantly different from the baseline value after 5 years. The high CRF group did not show any significant increase over time relative to the baseline value, but most patients in the high CRF group maintained relatively appropriate CRF levels after 5 years.

Conclusion Continuous support should be provided to patients to maintain optimal CRF levels after completing a CR program.

Keywords Acute coronary syndrome, Cardiorespiratory fitness, Cardiac Rehabilitation, Exercise test

Received June 23, 2020; Revised August 18, 2020; Accepted October 14, 2020; Published online April 30, 2021

Corresponding author: Jin Hyuk Jang

Department of Rehabilitation Medicine, Sanggye Paik Hospital, Inje University College of Medicine, 1342 Dongil-ro, Nowon-gu, Seoul 01757, Korea. Tel: +82-2-950-1145, Fax: +82-2-950-1144, E-mail: wkdwlsgur7@naver.com

ORCID: Chul Kim (https://orcid.org/0000-0001-8223-2945); Hee Eun Choi (https://orcid.org/0000-0002-8753-929X); Jin Hyuk Jang (https://orcid. org/0000-0003-2190-1054); Jun Hyeong Song (https://orcid.org/0000-0001-9003-0032); Byung-Ok Kim (https://orcid.org/0000-0002-7920-2750).

(c) This is an open-access article distributed under the terms of the Creative Commons Attribution Non-Commercial License (http://creativecommons.org/ licenses/by-nc/4.0) which permits unrestricted noncommercial use, distribution, and reproduction in any medium, provided the original work is properly cited. Copyright () 2021 by Korean Academy of Rehabilitation Medicine 


\section{INTRODUCTION}

Cardiac rehabilitation (CR) after acute coronary syndrome (ACS) can improve cardiopulmonary exercise capacity and help patients return to their daily routines and social activities, and improve their long-term prognosis [1-5].

According to the American Heart Association [6] and European Heart Association [7] guidelines, CR is a class IA recommendation for patients who undergo percutaneous coronary intervention (PCI) or coronary artery bypass graft (CABG) surgery for myocardial infarction (MI).

A systematic literature review and meta-analysis of patients with acute MI, PCI, or CABG, angina pectoris, and coronary artery stenosis confirmed on angiography showed that exercise-based CR reduced cardiovascular mortality and the risk of hospital readmission [8-11].

To maintain an adequate cardiopulmonary exercise (CPX) capacity, patients with ACS can be divided into two groups, those who exercised in center-based CR (CBCR) programs after discharge and those who exercised near their residence through home-based CR (HBCR) programs after training in the exercise method.

According to a Cochrane Review [12], no significant differences in cardiopulmonary function maintenance and exercise effects were found between the CBCR and HBCR groups. Recently, CBCR programs have been implemented mainly at university hospitals in South Korea; however, long-term studies on the cardiopulmonary fitness (CRF) level and prognosis with CBCR and HBCR are insufficient.

If the long-term prognosis of patients with ACS is not properly understood, the need for long-term management after an acute disease can be underestimated. Therefore, the long-term prognosis after the discharge of ACS patients must be confirmed.

The purpose of this study was to retrospectively investigate whether CBCR and HBCR groups maintained the optimal CRF level and provide information on the need for active participation in CR programs by reviewing patients' electronic medical records (EMRs).

\section{MATERIALS AND METHODS}

\section{Study design}

This study was performed retrospectively by analyz- ing patients' EMRs and was conducted at a single center (Inje University Sanggye Paik Hospital). Patient privacy and data confidentiality were maintained throughout the research process. The Institutional Review Board of the corresponding author's affliated Inje University approved the study (IRB No. 2020-01-008-001). The informed consent was waived.

\section{Subjects}

Eligible study participants were patients diagnosed with ACS (unstable angina, ST elevation MI, and non-ST elevation MI) who underwent CABG or PCI and visited our cardiac rehabilitation clinic after discharge. Patients who met the following criteria were included in the study: (1) patients with ACS who underwent CABG or PCI between January 2009 and December 2013; (2) participants of a CR program, regardless of whether it was CBCR or HBCR; and (3) patients who underwent regular checkup and follow-up CPX tests for at least 5 years. The exclusion criteria were as follows: (1) patients who had been treated or underwent surgery for heart disease other than coronary artery disease (e.g., cardiac valve disease); (2) inability to ambulate due to physical problems (paresis induced by cerebral stroke, spinal cord injury, amputation, severe pain, dyspnea, etc.); and (3) incomplete EMR. Patients who wanted to participate in the CR program in the hospital setting were assigned to the CBCR group and those who could not participate in the hospital CR program were assigned to the HBCR group unless they were categorized as "high-risk" according to the risk classification for exercise training, as established by the American Association of Cardiovascular and Pulmonary Rehabilitation [13]. The CBCR group participated in the CR program at least three times in the hospital over a 6to 8-week period. The HBCR group were educated in the CR exercise method immediately after discharge and performed self-exercises near their residence. The subject selection flow is shown in Fig. 1.

\section{Methods}

According to the contents of the EMRs, CR exercise was performed under supervision at a single CR center using a standardized protocol. The patients were instructed to visit our CR clinic for preliminary examination, including a CPX test, during their first visit. A real-time recording 12-channel electrocardiography (CASE; GE-Marquette, 


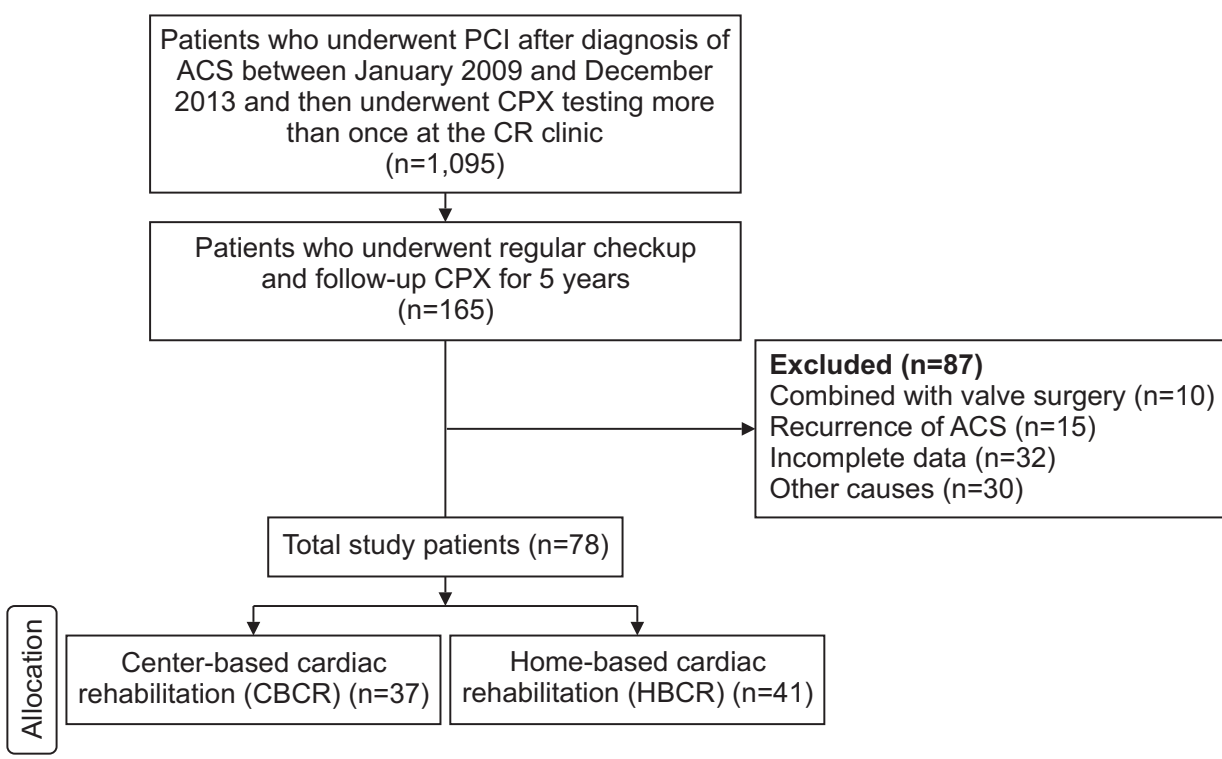

Fig. 1. Flow diagram of the study participants. ACS, acute coronary syndrome; PCI, percutaneous coronary intervention; CABG, coronary artery bypass graft; $\mathrm{CPX}$, cardiopulmonary exercise; $\mathrm{CR}$, cardiac rehabilitation.
Waukesha, WI, USA), respiratory gas analyzer (Quark CPET; COSMED Co., Rome, Italy), automatic blood pressure and pulse monitor (TANGO M2; SunTech Medical Inc., Morrisville, NC, USA), and treadmill (T-2100; GEMarqutte) were used in the CPX test. To assess changes in the cardiopulmonary capacity in the CPX test, variables such as maximal oxygen consumption $\left(\mathrm{VO}_{2 \max }\right)$, maximal metabolic equivalents $\left(\mathrm{METs}_{\max }\right)$, oxygen consumption at anaerobic threshold $\left(\mathrm{VO}_{2 \mathrm{AT}}\right)$, submaximal rate pressure product $\left(\mathrm{RPP}_{\text {at_stage } 3}\right)$, submaximal rate of perceived exertion $\left(\mathrm{RPE}_{\text {at_stage } 3}\right)$, resting and maximal heart rate $\left(\mathrm{HR}_{\text {rest }}\right.$ and $\mathrm{HR}_{\max }$, respectively), and resting systolic and diastolic blood pressures $\left(\mathrm{SBP}_{\text {rest }}\right.$ and $\mathrm{DBP}_{\text {rest }}$, respectively) were measured.

An exercise program based on the results of the CPX test was prescribed for the patients in the CBCR group and performed in accordance with the modified Bruce protocol within a week of discharge for the PCI cases or 4 weeks after CABG surgery. The patients attended a supervised exercise program consisting of 18 sessions, with 2-3 sessions per week, for over 2 months in a hospital setting. The exercise intensity of each session was increased in a stepwise manner on the basis of the target heart rate. The target heart rate was supposed to be $60 \%-85 \%$ of the heart rate reserve value, which can be calculated using the maximum and stable heart rates obtained from the CPX test. Each exercise session was divided into a 10-minute warm-up, 30-minute prescribed exercise, and 10-minute cooldown period. After completing the pro- gram, we advised the patients to participate in self-exercise programs based on their target heart rate and rate of perceived exertion measured in the follow-up CPX test.

An exercise program was prescribed for the patients in the HBCR group based on their CPX test results within a week of discharge for the PCI cases or 4 weeks after CABG surgery. The patients chose to participate in home-based exercise programs with exercise education through one or two monitoring exercises after the first CPX test in the hospital. The main reasons were time conflicts and the long distance of their residents from the hospital. However, patients who had a high risk of exercise-related cardiovascular events were not permitted to join the HBCR group. HBCR training consisted of following the exercise program with a frequency of 5-6 non-consecutive days per week and a duration of approximately 1 hour per day. The warm-up consisted of 5 minutes of light stretching, and 3-5 minutes of easy cycling, followed by an exercise session of a maximum of 40 minutes and 5-10 minutes cooldown period. The type of prescribed exercise included fast walking, power walking, cycling, and jogging, depending on the individual's exercise capacity and systemic conditions. The initial work intensity was $60 \%$, increasing to $85 \%$ of the maximum heart rate reserve or functional capacity. To patients were trained to check their radial pulses by counting how many times the radial artery beat every 10 seconds. The self-exercise prescriptions were the same as those for the CBCR group.

All the patients who participated in the CR program 
were educated on risk factor management and smoking cessation and were provided obesity [14] and nutrition consultations. In addition, the patients in both groups visited the CR clinic regularly several times during the first year after the ACS event and then every year to undergo follow-up CPX tests. To increase patient compli-

Table 1. Characteristics of the patients in the CBCR and HBCR groups

\begin{tabular}{|c|c|c|c|}
\hline Characteristic & $\operatorname{CBCR}(n=37)$ & HBCR $(n=41)$ & p-value \\
\hline Age (yr) & $63.5 \pm 9.3$ & $62.1 \pm 9.6$ & 0.53 \\
\hline Sex & & & 0.29 \\
\hline Male & 28 & 35 & \\
\hline Female & 9 & 6 & \\
\hline $\operatorname{BMI}\left(\mathrm{kg} / \mathrm{m}^{2}\right)$ & $24.8 \pm 3.6$ & $26.2 \pm 3.2$ & 0.09 \\
\hline $\operatorname{LVEF}(\%)$ & $58.5 \pm 12.7$ & $57.9 \pm 10.4$ & 0.83 \\
\hline \multicolumn{4}{|l|}{ Exercise capacity } \\
\hline $\mathrm{VO}_{2 \max }(\mathrm{mL} / \mathrm{kg} / \mathrm{min})$ & $26.4 \pm 6.4$ & $30.4 \pm 7.8$ & $0.02^{*}$ \\
\hline $\mathrm{METs}_{\max }$ & $7.6 \pm 1.8$ & $8.9 \pm 2.6$ & $0.01^{*}$ \\
\hline $\mathrm{VO}_{2 \mathrm{AT}}$ & $15.3 \pm 4.5$ & $15.7 \pm 3.4$ & 0.73 \\
\hline \multicolumn{4}{|l|}{ Smoking history } \\
\hline Never & $22(59.5)$ & $13(31.7)$ & $0.01^{*}$ \\
\hline Ex-smoker & $6(16.2)$ & $10(24.4)$ & 0.37 \\
\hline Current & $9(24.3)$ & $18(43.9)$ & 0.07 \\
\hline \multicolumn{4}{|l|}{ Cardiac diagnosis } \\
\hline STEMI & $16(43.3)$ & $14(34.2)$ & 0.41 \\
\hline Non-STEMI & 7 (18.9) & $12(29.3)$ & 0.29 \\
\hline Unstable angina & $14(37.8)$ & $15(36.5)$ & 0.91 \\
\hline \multicolumn{4}{|l|}{ Comorbidity } \\
\hline Hypertension & $21(56.8)$ & $21(56.8)$ & 0.48 \\
\hline \multicolumn{4}{|l|}{ Diabetes mellitus } \\
\hline None & $28(75.7)$ & $30(73.2)$ & 0.80 \\
\hline Non-IDDM & $8(21.6)$ & $10(24.4)$ & 0.76 \\
\hline IDDM & $1(2.7)$ & $1(2.4)$ & 0.35 \\
\hline Dyslipidemia & $13(35.1)$ & $12(29.3)$ & 0.58 \\
\hline Heart failure & $4(10.8)$ & $2(4.9)$ & 0.59 \\
\hline Others & $5(13.5)$ & $8(19.5)$ & 0.66 \\
\hline None & 7 (18.9) & $5(12.1)$ & 0.95 \\
\hline \multicolumn{4}{|l|}{ Revascularization } \\
\hline PCI & $35(94.6)$ & $39(95.1)$ & 0.56 \\
\hline CABG & $2(5.4)$ & $2(4.9)$ & 0.91 \\
\hline Number of diseased vessels & $1.57 \pm 0.7$ & $1.63 \pm 0.8$ & 0.71 \\
\hline Number of inserted stents & $1.24 \pm 0.7$ & $1.12 \pm 0.6$ & 0.39 \\
\hline Number of follow-up CPX test & $9.1 \pm 1.8$ & $10.0 \pm 2.5$ & 0.72 \\
\hline
\end{tabular}

Values are presented as mean \pm standard deviation or number (\%).

CBCR, center-based cardiac rehabilitation; HBCR, home-based cardiac rehabilitation; BMI, body mass index; LVEF, left ventricle ejection fraction; $\mathrm{VO}_{2 \max }$, maximal oxygen consumption; $\mathrm{METs}$ max , maximal metabolic equivalents; $\mathrm{VO}_{2 \mathrm{AT}}$, oxygen consumption at anaerobic threshold; STEMI, ST-segment elevation myocardial infarction; IDDM, insulin-dependent DM; PCI, percutaneous coronary intervention; CABG, coronary artery bypass graft; CPX, cardiopulmonary exercise. ${ }^{*} \mathrm{p}<0.05$. 
ance with self-exercises, when the patients came for their follow-up CPX tests, their attending physician motivated them to continue their exercise, and re-education was conducted after checking the previous self-exercise methods. In addition, prescriptions for exercise methods, including the updated target heart rate based on the CPX test results were distributed to patients in the form of hand-outs; these efforts ensured that self-exercise compliance was maintained as high as possible. Study outcomes were measured using the CPX test at baseline and follow-up (3, 6, and 12 months and every year thereafter) after initiating CR. The extent of improvement and the pattern of cardiopulmonary capacity $\left(\mathrm{VO}_{2 \max }, \mathrm{METs}_{\max }\right.$, etc.) were compared between the two groups at baseline, 12 weeks, 6 months, 1 year, 3 years and 5 years.

\section{Statistical analyses}

Data were analyzed using SPSS version 25 (IBM SPSS, Armonk, NY, USA). To compare the baseline characteristics of the two groups, the Student t-test was used. A paired t-test was performed to compare the parameters, including $\mathrm{VO}_{2 \max }, \mathrm{VO}_{2 \mathrm{AT}}, \mathrm{METs}_{\max }, \mathrm{RPP}_{\text {at_stage3}}$, and $\mathrm{RPE}_{\mathrm{at}}$ stage3, before and after the CR program. To determine the presence of an association between time and the METs $s_{\max }$ of the various groups, a repeated-measure analysis of variance (ANOVA) model was performed. For analysis over time, the variables representing CRF (e.g., $\mathrm{METs}_{\max }$ ) were analyzed using a two-way repeated measures ANOVA. Statistical significance was defined as $\mathrm{p}<0.05$.

\section{RESULTS}

\section{Baseline characteristics of the subjects}

The comparison of the demographic data between the two groups did not reveal any significant differences $(\mathrm{p}>0.05)$ (Table 1). However, the exercise capacity $\left(\mathrm{VO}_{2 \max }\right)$ at baseline in the CBCR group was significantly lower than that in the HBCR group $(26.4 \pm 6.4 \mathrm{~mL} / \mathrm{kg} / \mathrm{min}$ vs. $30.4 \pm 7.8 \mathrm{~mL} / \mathrm{kg} / \mathrm{min} ; \mathrm{p}=0.02)$. $\mathrm{METs}_{\max }$ at baseline was also significantly lower in the CBCR group than in the HBCR group ( $7.6 \pm 1.8$ vs. $8.9 \pm 2.6, \mathrm{p}=0.01$ ) (Table 2 ). The patients were predominantly male in both groups. The CBCR group included 37 patients (28 men and 9 women) with a mean age of $63.5 \pm 9.3$ years. The HBCR group included 41 patients ( 35 men and 6 women) aged $62.1 \pm 9.6$ years. The mean body mass index $\left(\mathrm{kg} / \mathrm{m}^{2}\right)$ at baseline in

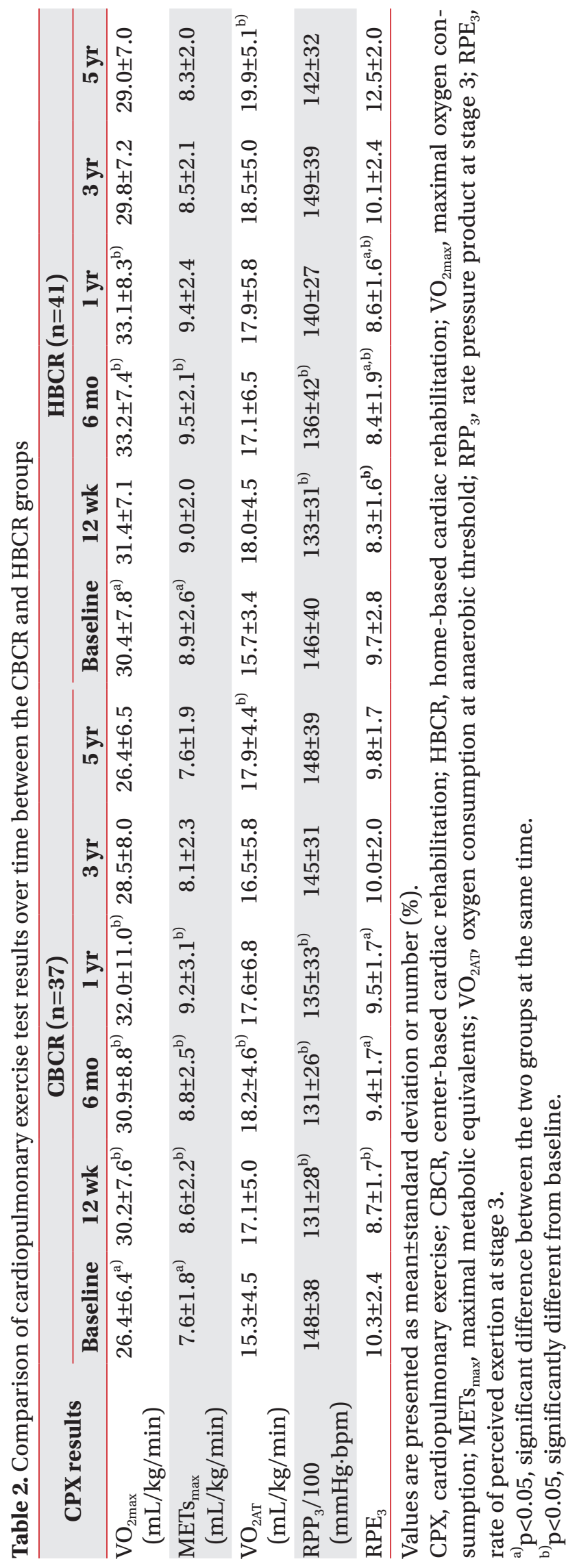


the HBCR group was higher than that in the CBCR group, but the difference between the two groups was not significant (26.2 \pm 3.2 vs. $24.8 \pm 3.6 ; \mathrm{p}=0.09)$.

\section{Comparison of CRF over time between the CBCR and HBCR groups}

Likewise, the changes in the CPX results from baseline in the CRF state ( $\mathrm{METs}_{\max }, \mathrm{VO}_{2 \max }$ ) and myocardial oxygen demand (e.g., RPP) for the CBCR and HBCR groups are presented in Table 2. In the follow-up CPX tests in the CBCR group, both $\mathrm{VO}_{2 \max }$ and METs $\mathrm{Max}_{\text {max }}$ increased significantly after 12 weeks $(30.2 \pm 7.6$ and $8.6 \pm 2.2 \mathrm{~mL} / \mathrm{kg} / \mathrm{min}$, respectively), and peaked at 1 year $(32.0 \pm 11.0$ and $9.2 \pm 3.1 \mathrm{~mL} /$ $\mathrm{kg} / \mathrm{min}$, respectively) after baseline $(\mathrm{p}<0.05)$ (Table 2, Fig. 2). In the HBCR group, both $\mathrm{VO}_{2 \max }$ and METs $\mathrm{Max}_{\max }$ increased significantly and peaked at 6 months (33.2 \pm 7.4 and 9.5 \pm 2.1 $\mathrm{mL} / \mathrm{kg} / \mathrm{min}$, respectively) after baseline, and were well maintained up to 1 year $(32.1 \pm 8.3$ and $9.4 \pm 2.4 \mathrm{~mL} / \mathrm{kg} /$ $\mathrm{min}$, respectively) after baseline ( $\mathrm{p}<0.05)$ (Table 2). After 1 year, both $\mathrm{VO}_{2 \max }$ and $\mathrm{METs}_{\max }$ showed a downward trend up to 5 years in both groups. However, in the HBCR group, the values at 5 years $\left(\mathrm{VO}_{2 \max } 29.0 \pm 7.0 ; \mathrm{METs}_{\max } 8.3 \pm 2.0\right)$ were lower than the baseline values but not significantly (p>0.05) (Fig. 2).

In the CBCR and HBCR groups, the $\mathrm{RPP}_{\text {at_stage } 3} / 100$ was significantly lower at 12 weeks $(131 \pm 28$ and $133 \pm 31$

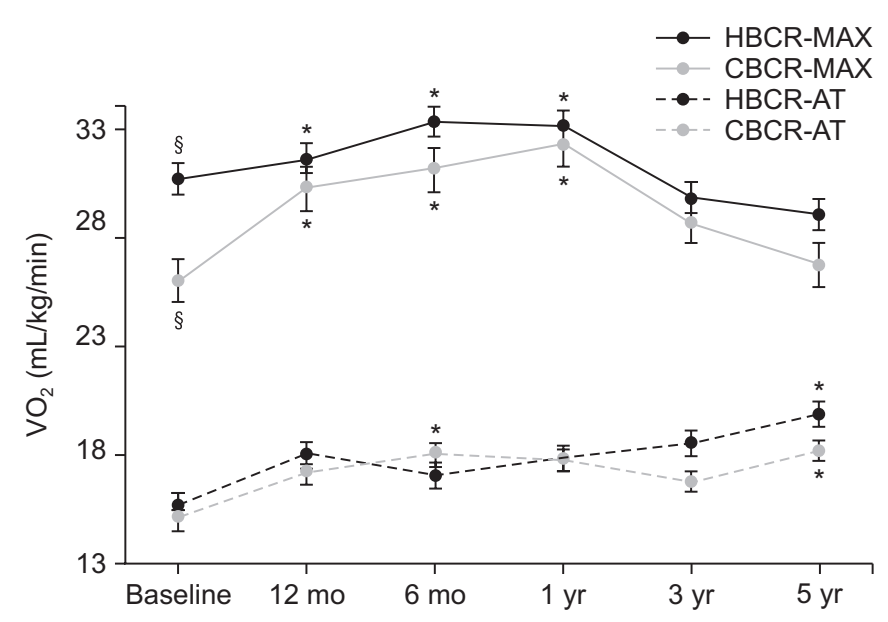

Fig. 2. Five-year trends of $\mathrm{VO}_{2 \max }$ and $\mathrm{VO}_{2 \mathrm{AT}}$ in the $\mathrm{CBCR}$ and HBCR groups. CBCR, center-based cardiac rehabilitation; HBCR, home-based cardiac rehabilitation; MAX, maximal oxygen consumption; AT, oxygen consumption at anaerobic threshold. ${ }^{\circledR} \mathrm{p}<0.05$, significant difference between the two groups at the same time. ${ }^{*} \mathrm{p}<0.05$, significantly different from the baseline value.

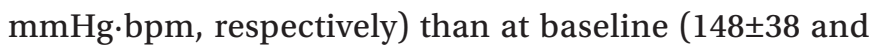
$146 \pm 40 \mathrm{mmHg} \cdot \mathrm{bpm}$, respectively). The $\mathrm{RPP}_{\text {at_stage } 3} / 100$ values at 5 years returned to near-baseline values in both groups (CBCR 148 \pm 39 ; HBCR 142 \pm 32 ) (Table 2).

No significant difference in $\mathrm{VO}_{2 \mathrm{AT}}$ at baseline was found between the two groups (CBCR $15.3 \pm 4.5 \mathrm{~mL} / \mathrm{kg} / \mathrm{min}$; HBCR $15.7 \pm 3.4 \mathrm{~mL} / \mathrm{kg} / \mathrm{min} ; \mathrm{p}>0.05)$. In the CBCR group, the $\mathrm{VO}_{2 \mathrm{AT}}$ at 6 months $(18.2 \pm 4.6 \mathrm{~mL} / \mathrm{kg} / \mathrm{min})$ and 5 years $(17.9 \pm 4.4 \mathrm{~mL} / \mathrm{kg} / \mathrm{min})$ were significantly higher than the baseline values $(\mathrm{p}<0.05)$. In the $\mathrm{HBCR}$ group, the $\mathrm{VO}_{2 \mathrm{AT}}$ at 12 weeks $(18.0 \pm 4.5 \mathrm{~mL} / \mathrm{kg} / \mathrm{min})$ and 5 years $(19.9 \pm 5.1$ $\mathrm{mL} / \mathrm{kg} / \mathrm{min}$ ) were also significantly higher than the baseline values $(\mathrm{p}<0.05)$ (Table 2, Fig. 2).

\section{Comparison of follow-up MET values over time between} the baseline CRF levels of the CBCR and HBCR groups

Based on the METs $s_{\max }$ value in the baseline CPX test, we classified the patients into the low, average, and high CRF groups regardless of the CR program they participated in [14-17]. The low CRF group included patients with $\leq 6$ METs $(n=11)$; the average CRF group included patients with 6-8 METs ( $\mathrm{n}=31$ ); and the high CRF group included patients with $\geq 8$ METs ( $n=36$ ) (Fig. 3, Table 3).

The METs $s_{\max }$ values in the low CRF group increased significantly and peaked at 1 year $(7.2 \pm 2.2 \mathrm{~mL} / \mathrm{kg} / \mathrm{min})$ after baseline $(\mathrm{p}<0.05)$. After 1 year, the METs $\mathrm{max}_{\max }$ values showed a downward trend to 5 years after baseline; however, the value at 5 years $(6.3 \pm 1.4 \mathrm{~mL} / \mathrm{kg} / \mathrm{min})$ was still significant-

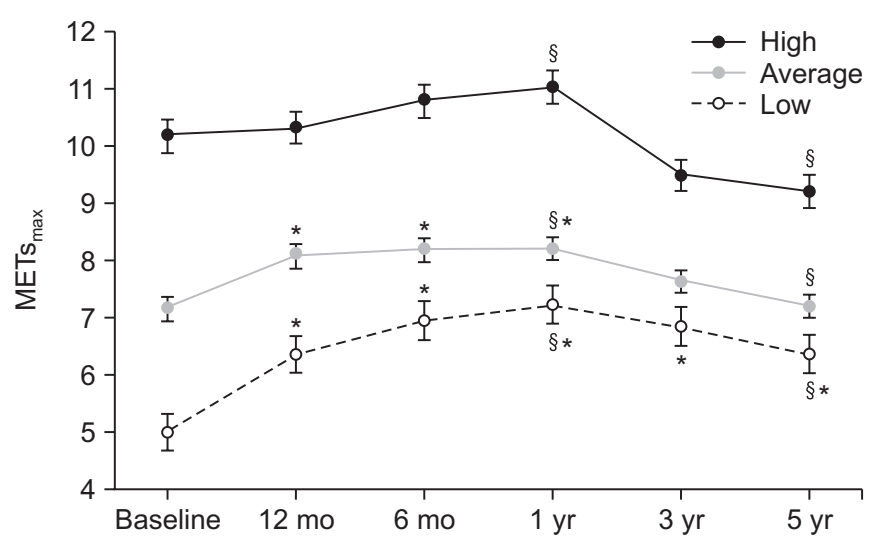

Fig. 3. Five-year trends of maximal metabolic equivalents $\left(\mathrm{METs}_{\max }\right)$ in three cardiorespiratory fitness groups: high ( $\geq 8$ METs), average, ( $\geq 6$ METs and $<8$ METs), and low ( $<6$ METs). ${ }^{5} \mathrm{p}<0.05$, significant difference between two periods in the same group. ${ }^{*} \mathrm{p}<0.05$, significantly different from the baseline value. 
Table 3. Comparison of follow-up METs over time between the groups with different baseline CRF levels

\begin{tabular}{|c|c|c|c|c|c|c|}
\hline CRF & Baseline & 12 wk & $6 \mathrm{mo}$ & $1 \mathrm{yr}$ & 3 yr & $5 \mathrm{yr}$ \\
\hline High & $10.2 \pm 1.9$ & $10.2 \pm 1.7$ & $10.8 \pm 1.9$ & $11.0 \pm 2.6^{\mathrm{a})}$ & $9.5 \pm 2.1$ & $9.2 \pm 1.6^{\mathrm{a}, \mathrm{b})}$ \\
\hline Average & $7.1 \pm 0.6$ & $8.0 \pm 1.5^{\mathrm{b})}$ & $8.2 \pm 1.4^{\mathrm{b})}$ & $8.2 \pm 1.8^{\mathrm{a}, \mathrm{b})}$ & $7.6 \pm 1.6$ & $7.2 \pm 1.6^{\text {a) }}$ \\
\hline Low & $5.0 \pm 0.6$ & $6.7 \pm 1.5^{\mathrm{b})}$ & $6.9 \pm 1.8^{\mathrm{b})}$ & $\left.7.2 \pm 2.2^{\mathrm{a}, \mathrm{b}}\right)$ & $6.8 \pm 1.6^{\mathrm{b})}$ & $6.3 \pm 1.4^{\mathrm{a}, \mathrm{b})}$ \\
\hline
\end{tabular}

Values are presented as mean \pm standard deviation.

METs, metabolic equivalents; CRF, cardiorespiratory fitness.

${ }^{a} \mathrm{p}<0.05$, significant difference between the two periods at the same group.

${ }^{b)} \mathrm{p}<0.05$, significantly different from baseline.

ly higher than that at baseline $(\mathrm{p}<0.05)$. In the average CRF group, the $\mathrm{METs}_{\max }$ value at 12 weeks $(8.0 \pm 1.5 \mathrm{~mL} /$ $\mathrm{kg} / \mathrm{min}$ ) was significantly higher than the baseline value $(7.1 \pm 0.6 \mathrm{~mL} / \mathrm{kg} / \mathrm{min})$ and peaked at 1 year after baseline $(8.2 \pm 1.8 \mathrm{~mL} / \mathrm{kg} / \mathrm{min} ; \mathrm{p}<0.05)$. In the high CRF group, the METs $_{\max }$ value at 1 year $(11.0 \pm 2.6 \mathrm{~mL} / \mathrm{kg} / \mathrm{min})$ was not significantly different from the baseline value $(10.2 \pm 1.9$ $\mathrm{mL} / \mathrm{kg} / \mathrm{min}$ ) but showed an upward trend for the first year after baseline, like in the other groups. After 1 year, the METs $_{\max }$ values in the high CRF group decreased; however, the value at 5 years after baseline $(9.2 \pm 1.6 \mathrm{~mL} /$ $\mathrm{kg} / \mathrm{min}$ ) remained high ( $>8 \mathrm{METs}$ ).

Although not shown in Table 3, two patients in the low CRF group improved and moved to the high CRF group after 5 years, and three patients in the low CRF group improved and moved to the average CRF group after 5 years. More than half of the patients in the low CRF group ( $n=6$ ) remained as such after 5 years ( $\leq 6$ METs). However, none of the patients in the high CRF group whose METs $\mathrm{max}_{\max }$ decreased could be classified in the low CRF group after 5 years. The METs ${ }_{\max }$ values of most patients in the high CRF group maintained a relatively adequate CRF level $(>8$ METs) even after 5 years.

\section{DISCUSSION}

The purpose of this retrospective study was to clarify whether the CRF level was well maintained for 5 years depending on the type of CR in ACS patients who underwent revascularization (PCI or CABG). The CBCR group completed a hospital-based CR program over a period of 2 months early after discharge and then visited the hospital periodically to undergo CPX tests while maintaining CR exercise in their community. The HBCR group included patients who were educated on self-exercise methods for use at home for 2-3 months after discharge, and then visited the hospital periodically to undergo CPX tests while continuing CR exercise in their community.

We demonstrated several important findings. First, the CRF levels in both the CBCR and HBCR groups remained significantly higher than the baseline values for up to 1 year, but both groups showed a decline in CRF after 1 year, reaching a level, similar to the baseline by the fifth year. Regardless of the type of CR exercise performed, adequate CRF levels were maintained for up to 1 year; however, it was difficult to maintain improved CRF levels for a long time. Another long-term follow-up study [4] reported that patients who completed the hospital CR program showed a significant decrease in mortality after 5 years. In addition, in a 6-year follow-up study of lowrisk patients who had undergone CABG surgery, CRF and physical activity levels were high in both the CBCR and HBCR groups [18]. In this study, the CRF level could not be maintained at an optimal level for a long time; that is, the significant improvement in the CRF level during the early stages of the CR program gradually decreased over time. The individual's motivation to perform CR exercises during the early CR program seems to have decreased over time as they continued performing communitybased CR exercises on their own volition [19].

Although exercise capacity expressed in terms of METs is a common clinical measure of exercise tolerance, exercise capacity is strongly influenced by age and activity status [15]. Given the above-mentioned findings, if the ACS patients did not participate in any type of CR program, their MET values would have naturally decreased with advancing age, and they would have had lower CRF levels than the results of this study by the fifth year. Therefore, while maintaining the proper CRF level for a long period is difficult, any type of CR participation must be encouraged in ACS patients. The effects of HBCR programs using communication equipment on CRF levels 
and quality of life have been reported [20,21]. According to the results of these studies, HBCR using electronic devices for self-monitoring can replace CBCR in low-risk patient groups. This is expected to have sufficient cardiac rehabilitation effects in terms of exercise capacity, quality of life, and mortality.

Moreover, we found that the RPP at stage 3 in both groups also decreased significantly after CR. RPP refers to the work required of the heart, which closely parallels the systolic blood pressure and heart rate. Generally, regular exercise training lowers HR and BP responses during submaximal exercise and creates a rightward shift in the RPP. If steady exercise is performed throughout a CR program, the RPP shows the same decrease in workload at stage 3 . In other words, our findings indicate that the RPP in submaximal efforts decreased, and the resistance of cardiac function against exercise increased.

Second, we found that the baseline $\mathrm{VO}_{2 \max }(26.4 \pm 6.4$ vs. $30.4 \pm 7.8 \mathrm{~mL} / \mathrm{kg} / \mathrm{min}$ ) and METs $_{\max }(7.6 \pm 1.8$ vs. $8.9 \pm 2.6$ $\mathrm{mL} / \mathrm{kg} / \mathrm{min}$ ) were significantly different between the CBCR and HBCR groups. Patients who undergo PCI or $\mathrm{CABG}$ are required to undergo risk classification for exercise-related cardiovascular events according to their medical history and CPX test results [6]. As both groups were defined regardless of risk stratification, this could be the main reason for the inclusion of the high-risk group with a low initial CRF level in the CBCR group according to the risk classification.

Third, when the patients were categorized into low, average, and high CRF groups according to the initial CPX results $\left(\mathrm{METs}_{\max }\right)$ regardless of the CR group, all patients who changed from the low CRF group to the average or high CRF group after 5 years underwent hospital-based cardiac rehabilitation, and 6 patients who remained in the low CRF group after 5 years were in both CBCR and HBCR groups. Maintaining an adequate CRF level has been found to be important for prognosis, including prolonging survival $[10,14,22-27]$. METs or a $\mathrm{VO}_{2 \max }$ of $3.5 \mathrm{~mL} / \mathrm{kg} / \mathrm{min}$ is known as a biomarker of CRF $[1,28]$. According to previous studies [29,30], a $\mathrm{VO}_{2 \max }$ of $1 \mathrm{~mL} /$ $\mathrm{kg} / \mathrm{min}$ or a $10 \%$ gain in $\mathrm{VO}_{2 \max }$ has clinically significant benefits. This supports the finding that the patients in the low CRF group in the initial CPX test had the advantage of maintaining adequate CRF especially in the CBCR program. Moreover, in the high CRF group, the METs value in the fifth year decreased relative to the baseline; however, the values were still within the range of the high METs values, which means that a proper CRF level was maintained. Therefore, if patients in the high CRF group participate in any type of CR exercise program, they will attain a good prognosis.

This study has several limitations. First, it was a nonrandomized retrospective study. Although the patients were selected on the basis of extensive inclusion and exclusion criteria, heterogeneity may be present in the selected sample. Second, the sample size (78 patients) was relatively small and derived from a single center, which makes the study results difficult to generalize. Thus, a multicenter study is recommended and needed in the future. Third, the patients' adherence to the HBCR exercise program was not evaluated because it was difficult to objectively evaluate whether patients performed CR exercises in their communities.

In summary, the findings of this study suggest that the outcomes of the CBCR and HBCR groups were similar in terms of CRF improvement. However, both groups were unable to maintain adequate CRF levels for a long period of $>5$ years. CR requires comprehensive management of the patient's condition through counseling to improve the patient's lifestyle and exercise education. Thus, patients must visit the hospital periodically after 1 year to be motivated to continue CR exercises, and thereby maintaining an appropriate CRF level.

\section{CONFLICT OF INTEREST}

No potential conflict of interest relevant to this article was reported.

\section{AUTHOR CONTRIBUTION}

Conceptualization: Kim C, Jang JH. Methodology: Kim C, Jang JH. Formal analysis: Jang JH, Song JH, Choi HE. Project. Administration: Kim C, Kim BY. Visualization: Kim C, Choi HE. Writing - original draft: Jang JH. Writing - review and editing: Kim C, Jang JH, Song JH. Approval of the final manuscript: all authors.

\section{REFERENCES}

1. Oldridge NB, Guyatt GH, Fischer ME, Rimm AA. Cardiac rehabilitation after myocardial infarction. Com- 
bined experience of randomized clinical trials. JAMA 1988;260:945-50.

2. Jolliffe JA, Rees K, Taylor RS, Thompson D, Oldridge N, Ebrahim S. Exercise-based rehabilitation for coronary heart disease. Cochrane Database Syst Rev 2001;(1):CD001800.

3. Taylor RS, Brown A, Ebrahim S, Jolliffe J, Noorani H, Rees $\mathrm{K}$, et al. Exercise-based rehabilitation for patients with coronary heart disease: systematic review and meta-analysis of randomized controlled trials. Am J Med 2004;116:682-92.

4. Conn VS, Hafdahl AR, Moore SM, Nielsen PJ, Brown LM. Meta-analysis of interventions to increase physical activity among cardiac subjects. Int J Cardiol 2009;133:307-20.

5. Kim JH, Chae SC, Oh DJ, Kim HS, Kim YJ, Ahn Y, et al. Multicenter cohort study of acute myocardial infarction in Korea: interim analysis of the Korea Acute Myocardial Infarction Registry-National Institutes of Health Registry. Circ J 2016;80:1427-36.

6. Smith SC Jr, Benjamin EJ, Bonow RO, Braun LT, Creager MA, Franklin BA, et al. AHA/ACCF secondary prevention and risk reduction therapy for patients with coronary and other atherosclerotic vascular disease: 2011 update: a guideline from the American Heart Association and American College of Cardiology Foundation endorsed by the World Heart Federation and the Preventive Cardiovascular Nurses Association. J Am Coll Cardiol 2011;58:2432-46.

7. Ibanez B, James S, Agewall S, Antunes MJ, BucciarelliDucci C, Bueno H, et al. 2017 ESC Guidelines for the management of acute myocardial infarction in patients presenting with ST-segment elevation: the Task Force for the management of acute myocardial infarction in patients presenting with ST-segment elevation of the European Society of Cardiology (ESC). Eur Heart J 2018;39:119-77.

8. Fujimi K, Imaizumi T, Suematsu Y, Kitajima K, Ueda T, Ishida $\mathrm{T}$, et al. Differential prognostic impact between completion and non-completion of a 5-month cardiac rehabilitation program in outpatients with cardiovascular diseases. Int J Cardiol 2019;292:13-8.

9. Swift DL, Lavie CJ, Johannsen NM, Arena R, Earnest $\mathrm{CP}, \mathrm{O}$ 'Keefe JH, et al. Physical activity, cardiorespiratory fitness, and exercise training in primary and secondary coronary prevention. Circ J 2013;77:281-92.
10. Lawler PR, Filion KB, Eisenberg MJ. Efficacy of exercise-based cardiac rehabilitation post-myocardial infarction: a systematic review and meta-analysis of randomized controlled trials. Am Heart J 2011;162:57184.

11. Buckingham SA, Taylor RS, Jolly K, Zawada A, Dean SG, Cowie A, et al. Home-based versus centrebased cardiac rehabilitation: abridged Cochrane systematic review and meta-analysis. Open Heart 2016;3:e000463.

12. American Association of Cardiovascular and Pulmonary Rehabilitation. Guidelines for cardiac rehabilitation and secondary prevention programs. Champaign, IL: Human Kinetics; 2013.

13. Park HK, Kim KH, Kim JH, Song MK, Choi IS, Han JY. Comparison of obesity related index and exercise capacity between center-based and home-based cardiac rehabilitation programs. Ann Rehabil Med 2019;43:297-304.

14. Kodama S, Saito K, Tanaka S, Maki M, Yachi Y, Asumi $\mathrm{M}$, et al. Cardiorespiratory fitness as a quantitative predictor of all-cause mortality and cardiovascular events in healthy men and women: a meta-analysis. JAMA 2009;301:2024-35.

15. Kaminsky LA, Arena R, Myers J. Reference standards for cardiorespiratory fitness measured with cardiopulmonary exercise testing: data from the Fitness Registry and the Importance of Exercise National Database. Mayo Clin Proc 2015;90:1515-23.

16. Ross R, Blair SN, Arena R, Church TS, Despres JP, Franklin BA, et al. Importance of assessing cardiorespiratory fitness in clinical practice: a case for fitness as a clinical vital sign: a scientific statement from the American Heart Association. Circulation 2016;134:e653-99.

17. Ehrman JK, Brawner CA, Al-Mallah MH, Qureshi WT, Blaha MJ, Keteyian SJ. Cardiorespiratory fitness change and mortality risk among black and white patients: Henry Ford Exercise Testing (FIT) Project. Am J Med 2017;130:1177-83.

18. Smith KM, McKelvie RS, Thorpe KE, Arthur HM. Six-year follow-up of a randomised controlled trial examining hospital versus home-based exercise training after coronary artery bypass graft surgery. Heart 2011;97:1169-74.

19. Baek S, Ha Y, Mok J, Park HW, Son HR, Jin MS. Com- 
munity-based cardiac rehabilitation conducted in a public health center in South Korea: a preliminary study. Ann Rehabil Med 2020;44:481-92.

20. Lee YH, Hur SH, Sohn J, Lee HM, Park NH, Cho YK, et al. Impact of home-based exercise training with wireless monitoring on patients with acute coronary syndrome undergoing percutaneous coronary intervention. J Korean Med Sci 2013;28:564-8.

21. Huang K, Liu W, He D, Huang B, Xiao D, Peng Y, et al. Telehealth interventions versus center-based cardiac rehabilitation of coronary artery disease: a systematic review and meta-analysis. Eur J Prev Cardiol 2015;22:959-71.

22. Blair SN, Kohl HW 3rd, Barlow CE, Paffenbarger RS Jr, Gibbons LW, Macera CA. Changes in physical fitness and all-cause mortality: a prospective study of healthy and unhealthy men. JAMA 1995;273:1093-8.

23. Erikssen G, Liestol K, Bjornholt J, Thaulow E, Sandvik L, Erikssen J. Changes in physical fitness and changes in mortality. Lancet 1998;352:759-62.

24. Lee DC, Sui X, Artero EG, Lee IM, Church TS, McAuley $\mathrm{PA}$, et al. Long-term effects of changes in cardiorespiratory fitness and body mass index on all-cause and cardiovascular disease mortality in men: the Aerobics Center Longitudinal Study. Circulation 2011;124:2483-
90.

25. Myers J, Prakash M, Froelicher V, Do D, Partington S, Atwood JE. Exercise capacity and mortality among men referred for exercise testing. N Engl J Med 2002;346:793-801.

26. Balady GJ, Larson MG, Vasan RS, Leip EP, O’Donnell CJ, Levy D. Usefulness of exercise testing in the prediction of coronary disease risk among asymptomatic persons as a function of the Framingham risk score. Circulation 2004;110:1920-5.

27. Arthur HM, Smith KM, Kodis J, McKelvie R. A controlled trial of hospital versus home-based exercise in cardiac patients. Med Sci Sports Exerc 2002;34:154450.

28. Sandercock G, Hurtado V, Cardoso F. Changes in cardiorespiratory fitness in cardiac rehabilitation patients: a meta-analysis. Int J Cardiol 2013;167:894-902.

29. Wilson JR, Groves J, Rayos G. Circulatory status and response to cardiac rehabilitation in patients with heart failure. Circulation 1996;94:1567-72.

30. Kavanagh T, Mertens DJ, Hamm LF, Beyene J, Kennedy J, Corey $\mathrm{P}$, et al. Peak oxygen intake and cardiac mortality in women referred for cardiac rehabilitation. J Am Coll Cardiol 2003;42:2139-43. 